\title{
PERBANDINGAN PRODUKTIVITAS AYAM BROILER TERHADAP SISTEM KANDANG TERBUKA (Open House) DAN KANDANG TERTUTUP (Closed House) DI UD SUMBER MAKMUR KECAMATAN SUMBERREJO KABUPATEN BOJONEGORO
}

\author{
Eka Dwi Susanti ${ }^{1}$, Ir. Mufid Dahlan, MM$^{2}$, Drh. Dyah Wahyuning A. S.Pt ${ }^{3}$ \\ ${ }^{1}$ Mahasiswa Fakultas Peternakan \\ ${ }^{2}$ Dosen Pembimbing Utama \\ ${ }^{3}$ Dosen Pembimbing Pendamping \\ Program Studi Peternakan \\ Fakultas Peternakan, Universitas Islam Lamongan (UNISLA)
}

RINGKASAN

Penelitian dilaksanakan pada tanggal 20 Mei sampai 25 Juni tahun 2016 dilakukan penelitian di Kandang Terbuka (Open House) dan Kandang Tertutup (Closed House) di UD. Sumber Makmur Kecamatan Sumberrejo Kabupaten Bojonegoro.Tujuan penelitian ini adalah untuk mengetahui perbandingan produktivitas sistem Kandang Open House dan Kandang Closed House ternak ayam broiler di UD. Sumber Makmur Kecamatan Sumberrejo Kabupaten Bojonegoro. Teknik penelitian yang digunakan adalah jenis penelitian pengamatan secara langsung ke lapangan (Observasi). Pengambilan sampel dengan cara simple random sampling (sampling acak sederhana). Pengambilan sampel dengan simple random sampling dimana sampel dipilih secara acak dari jumlah yang ditentukan, untuk penelitian ini menggunakan 2 kandang penelitian yaitu, lokasi tersebut yakni 1 Kandang Open House dan 1 Kandang Closed House yang berada di UD. Sumber Makmur Kecamatan Sumberrejo Kabupaten Bojonegoro. Hasil penelitian menunjukkan bahwa Pertumbuhan Berat Badan untuk Kandang Open House adalah 1.725 gr/ekor dan untuk Kandang Closed House 1.962 gr/ekor dari pertumbuhan berat badan kedua Kandang tersebut adalah kandang Closed House, tingkat mortalitas/kematian dari kandang Open House sebesar 5\%, kandang Closed House sebesar 4\% dari populasi 100 ekor ayam broiler dan untuk FCR kandang Open House adalah 1,78 untuk FCR kandang Closed House adalah 1,80 untuk menetukan FCR memenuhi standart bila FCR semakin kecil maka FCR semakin Baik. Untuk IP (Indeks Performa) untuk Kandang Open House adalah 263,05\% dan kandang Closed House adalah 289,66\% dari jumlah Ip antara dua kandang tersebut tidak mencapai standart, dan untuk standart Ip adalah diatas 300\%. Dari kesimpulan menunjukkan bahwa untuk pertumbuhan berat badan antara kandang Open dan Closed House adalah kandang Closed House. Kematian 4\% untuk kandang CloseD House dan 5\% untuk kandang Open House. FCR kandang Closed House lebih besar dari pada kandang Open House.

\section{PENDAHULUAN}

Ayam broiler adalah istilah untuk menyebutkan strain ayam hasil budidaya teknologi yang memiliki karakteristik ekonomis dengan ciri khas pertumbuhan cepat sebagai penghasil daging, konversi pakan irit, siap dipotong pada usia relatif muda, serta menghasilkan kualitas daging berserat lunak (Murtidjo, 1987). Ditambahkan oleh Rasyaf, (1992) bahwa ayam broiler merupakan ayam pedaging yang mengalami pertumbuhan pesat pada umur 1-5 minggu dengan berat 1.3-1.6 $\mathrm{kg}$, walaupun laju pertumbuhannya belum maksimum karena ayam broiler dengan berat $\leq$ $1.3 \mathrm{~kg}$ mengalami kesulitan dalam pemasarannya. Menurut Tarmudji, (2004) keunggulan karakteristik ayam broiler menandakan bahwa ayam broiler merupakan strain unggul yang berasal dari daerah subtropis dan produktivitasnya tidak dapat disamakan bila dipelihara di daerah tropis.
Dalam pemeliharaan broiler banyak faktor lingkungan yang memengaruhi salah satunya kandang. Kandang merupakan tempat ayam tinggal dan beraktivitas sehingga kandang yang nyaman sangat berpengaruh terhadap pencapaian produktivitas yang baik. Ayam merupakan ternak yang bersifat homeotermis, artinya ayam akan selalu berusaha menjaga suhu tubuhnya tetap konstan, tidak mengikuti suhu lingkungan. Cara yang dipakai oleh ayam untuk mengurangi panas tubuh yaitu dengan radiasi, konduksi, konveksi dan evaporasi (North dan Bell, 1990).

Kandang merupakan salah satu bagian dari manajemen ternak unggas yang sangat penting untuk diperhatikan. Bagi peternak dengan sistem intensif, kandang merupakan salah satu penentu keberhasilan beternak. Fungsi utama dari pembuatan kandang adalah memberikan kenyamanan dan melindungi 
ternak dari panasnya sinar matahari pada siang hari, hujan, angin, udara dingin dan untuk mencegah gangguan seperti predator. Selain itu, kandang juga berfungsi untuk memudahkan tata laksana yang meliputi pemeliharaan dalam pemberian pakan dan minum, pengawasan terhadap ayam yang sehat dan ayam yang sakit, (Rasyaf, 2011).

Pada umumnya ada dua sistem perkandangan yaitu sistem kandang tertutup (closed house) dimana iklim mikro dalam kandang dapat diatur sesuai kebutuhan, tipe kandang lainnya adalah kandang terbuka (open house) dimana unsur mikro dalam kandang tergantung pada kondisi alam di sekitar lingkungan kandang. Kandang yang digunakan di Indonesia khususnya di peternakan ayam skala kecil adalah sistem kandang terbuka. Dalam sistem kandang terbuka ada dua tipe kandang yang digunakan yaitu kandang postal dan kandang panggung. Pada kandang postal lantai kandang dapat berupa tanah atau tembok yang dilapisi 2 dengan litter baik sekam, atau bahan lain yang bisa digunakan. Pada kandang panggung lantai kandang berupa slatt yang terbuat dari bilah bambu atau kayu sehingga lantai kandang terdapat celah yang memungkinkan dilakukannya pembuangan litter (Tammaludin, 2012).

Pemeliharaan broiler pada umumnya menggunakan kandang alas litter, termasuk pada kandang tipe closed house. Kelebihan lain dari kandang tipe Closed House adalah kapasitas atau populasi jauh lebih banyak, ayam lebih terjaga dari gangguan luar baik fisik, cuaca, maupun serangan penyakit, terhindar dari polusi, keseragaman ayam lebih bagus, dan pakan lebih efisien. Kandang tipe ini juga memberikan kemudahan karena kondisi angin akan lebih terkontrol dibandingkan dengan kandang tipe terbuka, dan kelemahan dari kandang Closed House adalah membutuhkan investasi dan beban operasional yang cukup tinggi untuk membangunnya. Selain itu kandang Closed House harus disertai dengan infrastruktur dan penguasaan teknologi yang baik. Kelebihan dari Kandang Open House adalah biaya operasional yang cukup murah untuk membangun kandang terbuka, dan untuk memaksimalkan fungsi ventiliasi karena intensitas angin relatif tinggi dan juga untuk memaksimalkan cahaya matahari yang juga mmaksimalkan intensitas yang tinggi. dan Kelemahan kandang Open House adalah
Kandang yang sangat dipengaruhi oleh kondisi lingkungan dari luar seperti panas kelembapan udara dan angin, terutama diIndonesia dengan iklim yang tropis yang terkadang perubahan cuacanya sangat ekstrim. Didaerah dataran rendah suhu sangat tinggi dan angin cukup kencang. Sementara itu didataran tinggi suhu sangat dingin disertai dengan kelembapan tinggi, (Tamalludin, 2012).

Menurut Ulfah dan Joko, (2011) menyatakan bahwa produktivitas ayam broiler menunjang secara optimal, yang perlu diperhatikan dalam memilih sistem kandang ayam broiler diantaranya desain, dan peralatan yang sesuai. Namun, pertimbang utamanya dilihat dari faktor biaya. Selanjutnya diikuti dengan kemudahan dalam mendapatkan bahan dan peralatan serta ketahanan bahan dan peralatan. Oleh, karena kandang harus tahan lama dengan menyediakan lingkungan yang nyaman bagi ayam broiler. Serta dapat dikontrol dengan mudah.

Di Kabupaten Bojonegoro populasi ternak ayam Broiler yang tertinggi di Kecamatan Sumberrejo dengan jumlah populasi ternak ayam broiler 183,000 dan yang terendah di Kecamatan Margomulyo dan Ngasem dengan jumlah populasi ternak ayam broiler 4,000 (Dinas Peternakan Kabupaten Bojonegoro, 2015), dan Di Kecamatan Sumberrejo populasi ternak ayam broiler yang tertinggi di Desa Sambongrejo, Wotan, Karangdowo dengan jumlah populasi ternak ayam broiler 30,000 dan yang terendah di Desa Mejuwet dengan jumlah populasi ternak ayam broiler 8,000 (Dinas Peternakan Kabupaten Bojonegoro, 2015). Menurut data diatas peternakan di Kecamatan Sumberrejo Kabupaten Bojonegoro, untuk itu penulis melakukan penelitian dengan judul Perbandingan Produktivitas Sistem Kandang Open House dan Closed House ternak Ayam Broiler di UD. Sumber Makmur Kecamatan Sumberrejo Kabupaten Bojonegoro.

\section{MATERI DAN METODE}

Materi dalam penelitian ini adalah Kandang ayam broiler dengan sistem kandang terbuka (Open House) dan sistem kandang terbuka (Closed House). Dengan populasi 25.000 ekor tiap satu kali masa panen, dengan menggunakan kandang Closed House, dan untuk kandang Open House dengan populasi 29.000 ekor tiap kali masa panen ternak Ayam 
Broiler di UD. Sumber Makmur Kec. Sumberrejo Kabupaten Bojonegoro.

\section{METODE PENELITIAN}

Metode penelitian yang digunakan adalah jenis metode pengamatan secara langsung (Observasi). Seperti yang disampaikan oleh Arikunto (2006) bahwa, observasi adalah teknik pengamatan data yang dilakukan dengan pengamatan secara langsung ke lapangan. Data yang digunakan dalam penelitian adalah data primer dan sekunder.

Menurut Arikunto (2006) Data primer adalah data yang diperoleh atau pengamatan langsung di lapangan oleh orang yang melakukan penelitian. Data primer didapat dari sumber informan yaitu individu yang dilakukan oleh peneliti misalnya hasil observasi/pengamatan langsung lapangan. Sedangkan data sekunder adalah data yang diperoleh atau dikumpulkan oleh orang yang melakukan penelitian dari sumber-sumber yang telah ada. Data yang digunakan untuk mendukung informasi primer yang telah diperoleh yaitu bahan pustaka, literature, penelitian terdahulu, buku, dan lain sebagainya.

\section{VARIABEL YANG DIAMATI}

Variabel ayam broiler yang diamati dalam penelitian ini adalah Perbandingan produktivitas sistem kandang terbuka (Open House) dan kandang tertutup (Closed House) yang meliputi Pertambahan Bobot Badan, Konsumsi Pakan/ Feed Convertion Ratio (FCR), Mortalitas/Kematian, Indeks Performa (IP).

\section{Analisis Statistik}

ANALISIS DATA

Analisis statistik adalah analisis yang digunakan untuk membahas data kuantitatif. Pengujian dengan hipotesis ini dilakukan teknik statistik parametik. Menurut Sugiyono (2003) Statistik parametik digunakan untuk menguji parameter populasi melalui statistik, pengertian statistik disini adalah data yang diperoleh dari sampel, karena teknik ini sesuai dengan data kuantitatif (Sugiyono, 2003). Analisis ini digunakan untuk mengetahui Perbandingan Produktivitas sistem kandang Open House dan kandang Closed House ayam broiler data yang didapat dari hasil pengamatan, dilanjutkan mengetahui perbandingan dengan Uji T (Sutrisno, 2002).

\section{Analisis Pengambilan Data}

1. Pertambahan Bobot Badan (PBB mingguan)

Pertumbuhan Berat Badan dengan rumus adalah sebagai berikut:

$\mathrm{PBB}(\mathrm{g})=\mathrm{BB}_{\mathrm{t}}(\mathrm{g})-\mathrm{BB}_{\mathrm{t}-1}(\mathrm{~g})$

Keterangan :

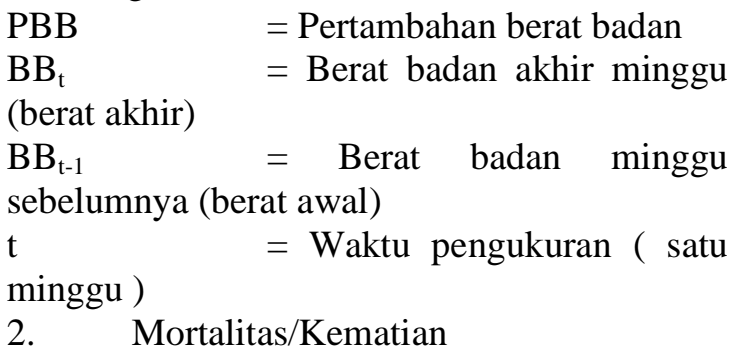

Mortalitas merupakan tingkat kematian dalam pemeliharaan selama satu kali produksi yang biasanya dihitung dalam presentase.

Mortalitas

$\frac{\text { Jumlah Ayam Mati }}{\text { Jumlah Dalam Keseluruhan Ayam }} \times 100 \%$

Sumber: (Santoso dan Sudaryani. 2009)

$3 . \quad$ Feed Convertion Ratio (FCR)

Perbandingan antara pakan yang dihabiskan dengan produksi bobot akhir. Rumus :

FCR $=\frac{\text { Bobot Pakan }(g r)}{\text { Bobot Badan }(g r)}$

Sumber : (Tamalludin. 2012)

4. Indeks Performa (IP)

Nilai Indeks Performa dapat diperoleh dengan cara sebagai berikut :

Indeks Performa

$=\frac{\text { Ayam Hidup } \times \text { Berat rata-rata }(\mathrm{Kg})}{\text { Umur Panen hari } x \text { Konversi pakan }} \times 100 \%$

\section{HASIL DAN PEMBAHASAN \\ 1. Pertumbuhan Berat Badan Mingguan (PBB)}

Dalam pemeliharaan ayam broiler pertumbuhan berat badan mingguan setiap ayam perlu diperhatikan. Hal ini dikarenakan agar produksi ayam saat memanen dapat stabil dan baik. Menurut Sudaryani (1997) untuk mendapatkan produksi yang baik perlu diadakan kontrol dengan penimbangan setiap minggunya. Apabila berat ayam belum memenuhi standar, maka jumlah pakan dapat ditambah dengan prosentase kekurangan berat badan standar. Akan tetapi bila bobot badan sudah memenuhi standar, maka jumlah pakan yang diberikan tetap sama dengan jumlah pakan yang diberikan sebelumnya.

Tabel 4. Pertumbuhan Berat Badan

\begin{tabular}{|c|c|c|}
\hline $\begin{array}{ll}\text { ggu } & \text { Min }\end{array}$ & $\begin{array}{c}\text { Open } \\
\text { House/gr/ekor }\end{array}$ & $\begin{array}{c}\text { Closed } \\
\text { House/gr/ekor }\end{array}$ \\
\hline
\end{tabular}




\begin{tabular}{|l|l|l|}
\hline I & 145 & 166 \\
\hline II & 408 & 441 \\
\hline III & 774 & 880 \\
\hline IV & 1.222 & 1.423 \\
\hline V & 1.725 & 1.962 \\
\hline Rat & & \\
a-rata & 265,9 & 298,0 \\
\hline
\end{tabular}

Sumber : Data Diolah

Dari Tabel 4 dapat dilihat bobot badan ayam pada Kandang Closed House memiliki perbedaan bobot badan ayam dibanding pada Kandang Open House data diatas menunjukkan bahwa untuk bobot badan Kandang Open House adalah 1.725 gr/ekor dan untuk Kandang Closed House adalah 1.962 gr/ekor dari kedua kandang tersebut mempunyai selisih sebesar 237 gr, dan bobot badan diatas sudah memenuhi bobot Badan standart adalah 1,854 gr, (PT. Charoen Pokphand, 2006).

Dari data diatas menunjukkan bahwa pertumbuhan berat badan pada ayam broiler yang tertinggi adalah Kandang Closed House dibandingkan Kandang Open House, karena untuk Kandang Closed House ternak ayam lebih terjaga dari gangguan luar baik fisik, cuaca, maupun serangan penyakit, terhindar dari polusi, keseragaman ayam lebih bagus, dan pakan lebih efisien, dan untuk Kandang Open House sangat dipengaruhi oleh kondisi lingkungan dari luar seperti panas kelembapan udara dan angin, dan pertambahan bobot badan ayam dipengaruhi oleh konsumsi pakan, jika konsumsi pakan baik, maka pertumbuhan juga akan baik. Hal ini sesuai dengan pendapat Abidin (2003) menyatakan bahwa faktor pertumbuhan berat badan adalah konsumsi pakan. Pendapat ini juga didukung oleh Ichwan (2003) yang menyatakan bahwa secara umum penambahan bobot badan akan dipengaruhi oleh jumlah konsumsi pakan yang dimakan dan kandungan nutrisi yang terdapat didalam pakan tersebut. Didapatkan uji T dari perbandingan pertumbuhan berat badan.

Tabel. 5 Uji T tabel dari Sampel 100 ekor ayam broiler:

\begin{tabular}{|c|c|c|}
\hline & $\mathrm{T}$ tab & \\
\hline hitung & $5 \%$ & $1 \%$ \\
\hline $\begin{array}{ll} & 0,0 \\
24 & \end{array}$ & $023^{1.66}$ & 422 \\
\hline
\end{tabular}
(2016)
Dari Tabel diatas bahwa menunjukkan untuk uji $\mathrm{T}$ hitung $<\mathrm{T}$ tabel sehingga untuk perbandingan berat badan ayam broiler dengan sistem kandang terbuka tidak berbeda nyata dengan sistem kandang tertutup.

\section{Mortalitas/Kematian}

Mortalitas atau angka kematian yaitu angka yang menunjukkan jumlah ayam yang mati selama pemeliharaan. Mortalitas merupakan faktor yang penting dan harus diperhatikan dalam suatu usaha pengembangan peternakan ayam. Menurut Bell dan Weaver (2002), tingkat kematian ayam banyak terjadi pada minggu-minggu pertama pemeliharaan dan sangat ditentukan oleh kondisi anak ayam pada saat pemeliharaan ayam. Tingkat mortalitas dipengaruhi oleh beberapa faktor diantaranya bobot badan, iklim, keberhasilan lingkungan, sanitasi peralatan kandang, dan penyakit.

Tabel 6.Tingkat Kematian/mortalitas ayam broiler

\begin{tabular}{|c|c|c|c|c|}
\hline \multirow[b]{2}{*}{ inggu } & \multicolumn{2}{|c|}{$\begin{array}{l}\text { Kandang } \\
\text { Terbuka }\end{array}$} & \multicolumn{2}{|c|}{$\begin{array}{l}\text { Kandang } \\
\text { Tertutup }\end{array}$} \\
\hline & \begin{tabular}{|l|}
\multicolumn{1}{|c|}{ umlah } \\
ematia \\
$\mathrm{n}$
\end{tabular} & $\begin{array}{l}\mathrm{P} \\
\text { rosenta } \\
\text { se (\%) }\end{array}$ & \begin{tabular}{l}
\multicolumn{1}{c}{$\mathrm{J}$} \\
umlah \\
Kemat \\
ian
\end{tabular} & $\begin{array}{l}\mathrm{P} \\
\text { rosenta } \\
\text { se (\%) }\end{array}$ \\
\hline & 3 & 3 & 2 & 2 \\
\hline I & 1 & 1 & 1 & 1 \\
\hline II & 1 & 1 & 0 & - \\
\hline V & 0 & - & 1 & 1 \\
\hline & 0 & - & 0 & - \\
\hline otal & 5 & 5 & 4 & 4 \\
\hline $\begin{array}{l}\text { ata- } \\
\text { rata }\end{array}$ & 1 & ,66 &, 8 & ,33 \\
\hline
\end{tabular}

Sumber : Data Diolah

Dari Tabel 6 untuk kematian/mortalitas ayam broiler dari kandang Open House untuk kematian/mortalitas dari 100 ekor ayam broiler untuk kematian sebesar 5 ekor ayam dan presentase kematian ayam broiler 5\% selama 1 periode. Dan untuk kematian/mortalitas Kandang Closed House dari 100 ekor ayam broiler mortalitasnya 4 ekor ayam dan untuk presentase kematian ayam 4\% selama satu periode, jadi tingkat kematian untuk Kandang Open House lebih banyak dari pada Kandang 
Closed House. Hal ini juga sesuai dengan Menurut North dan bell (1990), tingkat kematian sebesar 4-5\% tidak terlalu mempengaruhi biaya produksi, tetapi untuk kematian sebesar 20-30\% berpengaruh besar terhadap biaya produksi. Selanjutnya salah satu untuk menekan angka kematian adalah dengan memilih bibit ayam yang bermutu baik.

\section{Konversi Pakan/ Feed Convertion Ratio (FCR)}

Konversi pakan (FCR) merupakan ukuran membandingkan antara jumlah pakan yang dihabiskan dengan produksi daging dalam satu satuan waktu yang sama. Konversi pakan banyak yang digunakan oleh peternak guna mengukur kemampuan ternak dalam memanfaatkan pakan menjadi produk baik yaitu daging. Konversi pakan pada ayam broiler adalah banyaknya pakan yang dihabiskan oleh ayam dalam waktu tertentu untuk memproduksi daging. (Sarwono, 1991).

$$
\text { Tabel 7. Rata-rata Konsumsi, }
$$

Komulatif, BB dan FCR Kandang Open House dan Closed House.

\begin{tabular}{|c|c|c|c|c|c|c|c|c|}
\hline \multirow{3}{*}{$\begin{array}{l}\mathrm{Mi} \\
\mathrm{ng} \\
\mathrm{gu}\end{array}$} & \multicolumn{4}{|c|}{$\begin{array}{l}\text { Kandang } \\
\text { Open House }\end{array}$} & \multicolumn{4}{|c|}{$\begin{array}{l}\text { Kandang } \\
\text { House }\end{array}$} \\
\hline & $\begin{array}{l}\text { Ko } \\
\mathrm{m} \\
\text { ula } \\
\text { tif } \\
/ \mathrm{E} \\
\mathrm{ko} \\
\mathrm{r} / \mathrm{g} \\
\mathrm{r}\end{array}$ & $\begin{array}{l}\text { B } \\
\text { B/ } \\
\text { Ek } \\
\text { or/ } \\
\text { gr }\end{array}$ & CR & $F$ & $\begin{array}{r}\mathrm{K} \\
\text { omulatif } \\
\text { kor/gr }\end{array}$ & $\begin{array}{l}\text { B } \\
\text { Ekor/g }\end{array}$ & & CR \\
\hline & $\begin{array}{l}15 \\
4, \\
7\end{array}$ & $\begin{array}{l}14 \\
5\end{array}$ & ,06 & 1 & $78,8^{1}$ & 67 & & ,07 \\
\hline I & $\begin{array}{l}52 \\
9, \\
1\end{array}$ & $\begin{array}{l}40 \\
8\end{array}$ & ,29 & 1 & 92,2 & 41 & & ,34 \\
\hline II & $\begin{array}{l}1 . \\
14 \\
3\end{array}$ & $\begin{array}{l}77 \\
4\end{array}$ & ,47 & 1 & $294,3^{1 .}$ & 80 & & ,41 \\
\hline V & $\begin{array}{l}1 . \\
98 \\
0 \\
8\end{array}$ & $\begin{array}{l}1 . \\
22 \\
2\end{array}$ & ,62 & 1 & $219,6^{2 .}$ & .423 & & 61 \\
\hline & $\begin{array}{l}3 . \\
07 \\
7\end{array}$ & $\begin{array}{l}1 . \\
72 \\
5\end{array}$ & ,78 & & $541 \quad 3$. & .962 & & ,80 \\
\hline
\end{tabular}

Sumber : Data Diolah.

Berdasarkan Tabel 7 diatas menyatakan bahwa untuk Konversi Pakan/FCR (Feed
Convertion Ratio) untuk kandang terbuka dan tertutup pada ayam broiler semakin hari bertambahnya umur, maka konversi pakannya akan meningkat. Jadi konversi pakan untuk kandang terbuka pada minggu keenam adalah 1,78 dan untuk kandang tertutup pada minggu keenam 1,80. Konversi pakan antara kedua kandang tersebut bisa disimpulkan dari standart Konversi Pakan/FCR untuk Bobot Badan kandang terbuka adalah 1,725 gr dengan standart FCR 1,62, kemudian bobot badan untuk kandang tertutup adalah 1,962 gr dengan standart $F C R$ 1,78, dapat dihitung dengan cara sebagai berikut:

$F C R=F C R$ Standart - FCR Aktual, $=1,62-1,78=-0,16$ (Untuk Kandang Open House)

$$
=1,78-1,80=-0,02 \text { (Untuk Kandang }
$$

\section{Closed House)}

Dari hitungan diatas maka bisa dinyatakan bahwa jika $F C R$ kecil, maka $F C R$ semakin baik. Hal ini sesuai dengan pendapat Wawan, (2010). Sehingga semakin kecil angka konversi pakan menunjukkan semakin baik efesiensi penggunaan pakan. Bila angka perbandingan kecil berarti kenaikan berat badan memuaskan atau ayam maka tidak terlalu banyak untuk meningkatkan berat badannya. Faktor yang mempengaruhi besar kecilnya konversi pakan meliputi daya cerna ternak, kualitas pakan yang dikonsumsi serta keserasian nilai nutrient yang dikandung pakan tersebut. Dari hasil tersebut menunjukkan bahwa tingkat konsumsi pakan ayam broiler untuk membuat daging $1 \mathrm{~kg}$ maka $F C R$ Aktual lebih boros $0,16 \mathrm{~kg}$ pakan terhadap pertumbuhan berat badannya sudah cukup efisien dan baik.

\subsubsection{Indeks Performa (IP)}

. Indek performa (IP) adalah suatu formula yang umum digunakan untuk mengetahui performa ayam broiler. Semakin besar nilai IP yang diperoleh, semakin efesiensi penggunaan pakan (Fadilah, 2007).

Indeks Performa (IP) untuk Kandang Terbuka (Open House) adalah sebagai Berikut :

IP

$$
\begin{aligned}
& \begin{array}{l}
\text { Fcr } \times \text { Umur } \\
=
\end{array} \\
= & \frac{95 \times 0-7,51,75}{62,75} \times 100 \% \\
= & \frac{16.625}{62,3}
\end{aligned}
$$




$$
=263,05 \%
$$

Indeks Performa (IP) untuk Kandang Tertutup (Closed House) adalah sebagai berikut:

IP

$$
\begin{aligned}
& \frac{(100-\text { Kematian }) \times \text { Bobot Rata-rata }}{\text { Fcr } \times \text { Umur }} \times 100 \% \\
& =\frac{(100-4) \times 1,96}{1,80 \times 35} \times 100 \% \\
& =\frac{96 \times 1,96}{63} \times 100 \% \\
& =\frac{18.816}{63} \\
& =298,66 \%
\end{aligned}
$$

Berdasarkan hasil perhitungan diatas maka diperoleh data produksi atau indeks Performa (IP) adalah untuk kandang terbuka IP 263,05\% dan Untuk kandang tertutup IP 298,66\%, tetapi dari IP diatas untuk kandang Tertutup (Closed House) lebih baik dari pada kandang Terbuka (Closed House), meskipun keduanya dari hasil penelitian tidak bisa mencapai diatas $300 \%$. Hal ini sesuai dengan pendapat Fadilah, (2007) Semakin besar nilai IP yang diperoleh lebih dari $300 \%$ semakin bagus tingkat performa ayam dan semakin efesiensi penggunaan biaya.

\section{KESIMPULAN DAN SARAN 1. KESIMPULAN}

Berdasarkan dari hasil pembahasan tersebut dapat disimpulkan dipeternakan UD. Sumber Makmur Kecamatan Sumberrejo Kabupaten Bojonegoro, antara lain:

1. Berat Akhir yang tertinggi adalah Kandang Closed House dibanding dengan Kandang Open House. Untuk Uji T perbandingan berat badan ayam broiler dapat disimpulkan perbandingan produktivitas bisa disimpulkan tidak berbeda nyata.

2. Kematian/mortalitas yang tertinggi untuk kandang terbuka sebanyak $5 \%$ dan kandang tertutup adalah $4 \%$.

3. Konversi Pakan/FCR untuk kandang tertutup lebih besar dari pada kandang terbuka. Kandang tertutup FCRnya 1,80\%, Kandang tebuka FCRnya 1,78\%.

4. Untuk IP Kandang Open House 263,05\% dan untuk IP Kandang Closed House adalah $298,66 \%$.

\section{SARAN}

Saran yang ingin disampaikan oleh penulis berdasarkan kesimpulan tersebut bagi peternak untuk meningkatkan perbandingan produktivitas disarankan untuk menggunakan kandang Close House untuk mendapatkan hasil yang maksimal.

\section{DAFTAR PUSTAKA}

Abidin,Z. 2003. Meningkatkan Produktivitas Ayam Pedaging. Agromedia Pustaka. Jakarta

Arikunto, Suharsimi. 2006. Prosedur Penelitian. Jakarta. PT. Rineka Cipto

Fadillah. R, 2007. Sukses Berternak Ayam Broiler. PT.Agromedia Pustaka: Ciganjur.

Fitri, 2010, Statistik Untuk Penelitian. BPFE. Yogyakarta

Hardjosworo P S. dan Rukmiasih M. S. 2000. Meningkatkan Produksi Daging Unggas. Yogyakarta: Penebar Swadaya

Ichwan. 2003. Membuat Pakan Ayam Ras Pedaging. PT Agromedia Pustaka Utama. Jakarta

Kamara, T. 2009. Menghitung Indeks Performa Ayam Broiler.

Universitas Padjajaran. Bandung

Kartasudjana, R dan Edjeng. 2006. Manajemen Ternak Unggas. Yogyakarta

Martono A. P. 2004. Membuat Kandang Ayam. PT. Penebar Swadaya: Jakarta

Murtidjo, B. A. 1987. Pedoman Beternak Ayam Broiler. Penerbit Kanisius Yogyakarta.

Multi Medis Pratama. 2013.Kandang Closed

House.www.multimeditaspratama.c om. diakses tanggal 29 Januari 2016

Noor, Juliansyah. 2011. Metode Penelitian Skripsi, Tesis, Disertasi, Dan Karya Ilmiah. Prenadamedia Group. Jakarta.

North M.O. Bell D.D. 1990. Commercial Chicken Production Manual. 4th Edition Van Northland Reindhold New York. 
Nugroho, 2008, Kebutuhan Nutrisi Ayam Broiler. Malang : UMM Press

PT. Charoen Pokphan Indonesia. 2006. Manajemen Broiler. Kiat-Kiat Memperbaiki FCR. Technical Service Dan Development Department. Jakarta

Pangestika, 2011. Angka Mortalitas Pada Ayam Broiler. Ternak ayam broiler.blogspot.com

Rasyaf, M. 1992. Pengelolaan Peternakan Unggas Pedaging. Kanisius. Yogyakarta.

Rasyaf, M. 2011. Panduan Beternak Ayam Pedaging. Penerbit Swadaya. Jakarta

Santoso, H dan Sudaryani, T. 2009. Pembesaran Ayam Pedaging di Kandang Panggung Terbuka. Penebar Swadaya: Jakarta

Sarwono, B. 1991. Beternak Ayam Buras. Penebar Swadaya. Jakarta

Siregar. A. P. 1980. Teknik Beternak Ayam Pedaging Di Indonesia. Merdie Group. Jakarta

Sugiyono. 2003. Metode Penelitian Bisnis. Pusat Bahasa Depdiknas. Bandung

Sutrisno, H, 2002. Statistik Jilid 2. Penerbit Andi. Yogyakarta.

Tamalludin, Ferry. 2012. Ayam Broiler 22 Hari Panen Lebih Untung. Penebar Swadaya. Jakarta.

Tamalludin, Ferry. 2014. Panduan Lengkap Ayam Broiler. Penebar Swadaya. Jakarta.

Tarmudji. 2004. Mendeteksi munculnya ayam kerdil. Tabloid Sinar Tani (7 Juli 2004), Jakarta.

Tim Karya Tani Mandiri. 2009. Pedoman Budidaya Beternak Ayam Broiler. Bandung: Nuansa Aulia

Ulfah, M dan Joko D. S. 2011. 7 Jurus Menjadi Peternak Ayam Ras Pedaging. Penerbit Swadaya. Jakarta

Wawan, 2010. Pentingnya FCR Pada Ayam Broiler. Andiwawan_tonra. blogspot.com 